\title{
THE ROLE OF LOW DENSITY LIPOPROTEINS AS BASED EXTENDER IN BOVINE SEMEN CRYOPRESERVATION AND ITS EFFECT ON FERTILITY
}

\author{
${ }^{* 1}$ Abd El-Razek I.M., Entsar Z. Eid ${ }^{2}$, M.E. El-Sharawy ${ }^{1,3}$, E.M. El-Seify ${ }^{2}$ and I.S. El-Shamaa ${ }^{1 *}$ \\ 1- Animal Production Department, Faculty of Agriculture, Kafrelsheikh University, Egypt, 2- Animal \\ Production Research Institute, Agricultural Research Center, Ministry of Agriculture, Egypt, 3- Department \\ of Animal and Marine Bioresource Sciences, Faculty of Agriculture, Kyushu University, Japan. \\ *Corresponding authorE-mail: elshamaa2008@yahoo.com, ibrahimabdelrazek2006@yahoo.com
}

\section{SUMMARY}

The aim of the current study was to evaluate the cryopreservation effect of different concentrations of low density lipoproteins ( $L D L)$ (4, 6, 8 and 10\%), as a substitute for whole egg yolk (20\%) in Holstein bull semen extender and its effect on bull semen freezing and subsequent fertility. Semen was collected from four bulls twice weekly for 12 weeks and the ejaculates with more than $75 \%$ progressive motility and $85 \%$ normal morphology were pooled prior to cryopreservation. Semen was diluted at $37^{\circ} \mathrm{C}$ with Tris-citric acid extender to $8 \times 10^{7}$ motile spermatozoa/ml. Diluted semen was equilibrated at $4^{\circ} \mathrm{C}$ for $4 \mathrm{~h}$., filled in $0.25 \mathrm{ml}$ French straws and kept on liquid nitrogen vapors for $10 \mathrm{~min}$. Straws were plunged and stored in liquid nitrogen $\left(-196^{\circ} \mathrm{C}\right)$. Sperm motility, plasma membrane integrity and acrosome integrity were assessed at post-dilution, pre-freezing and post freezing-thawing. Results revealed that the $6 \%$ LDL concentration in semen extender was more effective $(P<0.05)$ in preservation of progressive motility, plasma membrane integrity and acrosome integrity of spermatozoa than control and the other LDL concentrations ( 8 and 10\%) at different cryopreservation processes. Fertility rates were higher $(P<0.05)$ in cows artificially inseminated with the semen cryopreserved in 4 and $6 \%$ LDL extenders (72.7 and 76.7\%) compared with that of control, 8 and 10\% LDL extenders (60, 61.5 and 58.3\%, respectively). It could be concluded that the 6\% LDL concentration in the extender was better able to protect the bovine sperm cell from cryodamage and improved cryopreserved semen quality and fertility.

Keywords: bovine, semen, LDL, freezing, fertility

\section{INTRODUCTION}

Freezing process exposes the spermatozoa to thermal shock, which results in damage to the plasma membrane and acrosome integrity (Celeghini et al., 2007). Various extenders have been tested in an attempt to limit cellular injury. Egg yolk is the most widely used in these extenders by A.I centers. Recently, centrifugation techniques have enabled the isolation of the LDL that is responsible for the cryopreservative effect of egg yolk (Moussa et al., 2002; Bergeron and Manjunath, 2006). The incorporation of LDL in bovine semen extenders has given an improvement in semen parameters compared with extenders containing whole egg yolk (20\%) (Moussa et al., 2002; Amirat-Briand et al., 2004 and 2010).

In canine semen, Bencharif et al. (2008) found that the $6 \%$ LDL extenders gave better motility results and did not cause any further damage to the flagella plasma membrane in comparison with the standard extenders containing whole egg yolk. In another study, Bencharif et al.(2010) observed that the $6 \%$ LDL extender provided the best protection of acrosome integrity in canine spermatozoa due to a direct action through the exchange or repair of acrosomal membrane phospholipids or, simply because the LDL medium is less rich in progesterone than the whole egg yolk because of dialysis. In addition, $\mathrm{Hu}$ et al. (2010) found that the 8 or $9 \%$
LDL extenders offered the highest intact acrosome and plasma membrane integrity than whole egg yolk (20\%) or 7 or $10 \%$ LDL extenders. Additionally, in buffalo spermatozoa, Akhter et al. (2011); ElSharawy et al. (2012a and 2012b) and El-Shamaa et al. (2013) found that LDL extenders have improved motility, plasma membrane integrity and acrosome integrity. The amount of LDL used as a component of semen freezing extender may differently influence the structural and functional parameters of the spermatozoa (Bergeron and Manjunath, 2006). Therefore, the aim of the present study was to demonstrate the cryopretective role of different LDL concentrations in semen extender to formulate an optimum concentration of LDL for better cryopreserved semen quality of Holstein bulls.

\section{MATERIALS AND METHODS}

\section{Semen collection:}

Four Holstein bulls belonging to the International Livestock Management training center (ILMTC), Sakha station, Animal Research Institute, Ministry of Agriculture, Egypt were used. These bulls were housed in individual boxes and fed on the recommended ration according to Animal production Research Institute (1997). All chemicals used in this study were purchased from Sigma (Sant Luis, MO, USA), unless otherwise indicated. Semen was collected twice weekly using an artificial vagina for a 
period of 12 weeks. After semen collection, the ejaculates that had more than $75 \%$ visual motility and $85 \%$ normal sperm morphology were pooled to have sufficient semen to make a replicates and to eliminate the bull effect (individual differences in bulls). The pooled ejaculates were immediately diluted to $8 \mathrm{x}$ 107 spermatozoa/ml using the five extenders that had been previously prepared and warmed to $37^{\circ} \mathrm{C}$ and then subjected to a progressive cooling from $37^{\circ} \mathrm{C}$ to $4^{\circ} \mathrm{C}$ for $4 \mathrm{~h}$ (equilibration period) in a refrigerator unit before being loaded into $0.25 \mathrm{ml}$ straws (IMV, L'Aigle, France). The straws were held for $10 \mathrm{~min}$ at $4 \mathrm{~cm}$ from the surface of the liquid nitrogen $\left(-120^{\circ} \mathrm{C}\right)$ before being immersed and then stored in liquid nitrogen $\left(-196^{\circ} \mathrm{C}\right)$ for $24 \mathrm{~h}$ of storage.

\section{Extenders preparation:}

Five extenders were prepared and stored at $4{ }^{\circ} \mathrm{C}$ until use. Tri-egg yolk extender (20\% EY, control) containing $20 \mathrm{ml}$ of hen's egg yolk, $3.025 \mathrm{~g}$ tris (hydroxylmethyl amino methane), $1.675 \mathrm{~g}$ citric acid, $0.75 \mathrm{~g}$ glucose, $7 \mathrm{ml}$ glycerol, $0.25 \mathrm{mg}$ lincomycin, $0.005 \mathrm{mg}$ streptomycin and $100 \mathrm{ml}$ bi-distilled water. However, LDL extenders containing 4, 6, 8 and $10 \%$ LDL were prepared from hen's egg yolk according to the method described by Moussa et al. (2002) and diluted in Tris extender control.

\section{Semen quality assays:}

All evaluations regarding the sperm parameters such as sperm motility, plasma membrane and acrosome integrity were performed for each extender at post dilution, pre-freezing (post equilibration) and post frozen-thawed spermatozoa. All recorded values representing the average of three evaluations per sample were conducted.

\section{Assessment of sperm motility:}

At post-dilution, pre-freezing and post-thawing, four straws from each extender were immersed in water bath at $37^{\circ} \mathrm{C}$ for $10 \mathrm{~s}$ and then, sperm motility was assessed using $5 \mu 1$ semen placed on pre-warmed glass slide and covered by a warmed cover slip. For each sample, at least five microscopic fields were examined for $10 \mu \mathrm{L}$ semen sample at a magnification of $400 \mathrm{x}$ using a phase-contrast inverted light microscope (CKX41; Olympus, Tokyo, Japan) with a warm stage maintained at $37^{\circ} \mathrm{C}$. The mean of the three successive evaluations at every stage of cryopreservation previously mentioned was recorded as the final motility score. At least 200 spermatozoa were counted per slide.

\section{Assessment of membrane and acrosome integrity:}

Membrane integrity was assessed using HypoOsmotic Swelling test (HOS) based on curled and swollen tail. The hypo-osmotic solution (150 osm/L) was prepared by dissolving $0.735 \mathrm{~g}$ Sodium citrate dihydrate and $1.35 \mathrm{~g}$ fructose in $100 \mathrm{ml}$ distilled water. A one $\mathrm{ml}$ of hypo-osmotic solution was mixed with $0.1 \mathrm{ml}$ of semen and incubated at $37^{\circ} \mathrm{C}$ for one hour. A drop of diluted semen was placed on a clean dry glass slide and covered by cover slip. A total of 100 spermatozoa were counted under a phase contrast microscope (400x magnification). The percentage of spermatozoa positive to HOS test (having curled and swollen tail) was determined (Jeyendran et al., 1984 and Lodhi et al., 2008). Whereas, sperm acrosomal integrity was estimated using Giemsa stain (Watson, 1975) and the microscopic examination was carried out using oil immersion lens (x1000).

\section{Fertility trial:}

A total of 295 Friesian cows owned by small and medium scale breeding holder in different villages at Kafr-elsheikh and Gharbya Governorates in Egypt were artificially inseminated with random frozen semen doses from the various extenders. Each female was inseminated with a single straw $10 \mathrm{~h}$ after starting estrous behavior. Using recto-vaginal technique and the universal insemination gun, the thawed semen was deposited in the uterine body just next to the anterior end of the cervix. Conception rate was confirmed by rectal palpation 60 days after insemination.

\section{Statistical analysis:}

The experimental data were statistically analyzed using the general model program (SAS, 1999). Data of semen parameters was subjected to repeated measurement according to the following model:

$\mathrm{Y}_{\mathrm{ijk}}=\mu+\mathrm{T}_{\mathrm{i}}+\mathrm{P}_{\mathrm{j}}+\mathrm{S}(\mathrm{P})_{\mathrm{ijk}}+\left(\mathrm{T}^{*} \mathrm{P}\right)_{\mathrm{ij}}+\mathrm{e}_{\mathrm{ijk}}$

Where:

$\mathrm{Y}_{\mathrm{ijk}}=$ any observation.

$\mu=$ overall mean.

$\mathrm{T}_{\mathrm{i}}=$ the fixed effect of the estimate.

$\mathrm{P}_{\mathrm{j}}=$ the fixed effect of sampling period $(1,2,3, \ldots)$.

$\mathrm{S}(\mathrm{P})_{\mathrm{ijk}}=$ sample within period.

$\left(\mathrm{T}^{*} \mathrm{P}\right)_{\mathrm{ij}}=$ the fixed effect of the interaction between Period of sampling and treatment.

$\mathrm{e}=$ error.

The least square mean was calculated by modulating the data higher than $70 \%$ and less than $30 \%$.

Differences with $\mathrm{P}<0.05$ were considered significant.

\section{RESULTS}

\section{Progressive sperm motility:}

At post-diluted, post-equilibrated and post-thawed semen, the sperm progressive motility was superior $(\mathrm{P}<0.05)$ for the semen diluted in the extender containing $6 \%$ LDL compared with that of the control (68.64 \% vs. $62.73 \%$, Table 1). Similarly, these parameters were found higher in $4 \%$ LDL extender than that of the control but the differences were not significant at post-equilibrated and post-thawed semen. On the other hand, sperm progressive motility was slightly lower $(\mathrm{P}>0.05)$ in 8 and $10 \% \mathrm{LDL}$ extenders than that of the control extender $(20 \% \mathrm{EY})$.

\section{Plasma membrane integrity:}

The mean percentages of swollen bull spermatozoa (intact plasma membrane) obtained for each extender during the different stages of cryopreservation are presented in Table (2). The $6 \%$ LDL extender gave a significantly $(\mathrm{P}<0.05)$ superior percentage of intact plasma membrane than control, 8 
and $10 \%$ LDL extenders at all of the three cryopreservation processes. However, the percentage of plasma membrane integrity showed slightly higher for spermatozoa cryopreserved in 6\% LDL extender than that in $4 \%$ LDL extender $(\mathrm{P}>0.05)$ except at the post dilution $(\mathrm{P}<0.05)$ process.

\section{Acrosome integrity:}

The mean percentages of acrosome integrity recorded for each extender after the different stages of cryopreservation are presented in Table (3).

The 4 and $6 \%$ LDL extenders had the highest percentages of acrosome integrity $(\mathrm{P}<0.05)$ when they were compared with that of the control extender at the all stages of cryopreservation. Therefore, the best percentage of acrosome integrity for the spermatozoa at all stages of cryopreservation process was found with $6 \%$ LDL extender.

\section{Fertility trial:}

Conception rates (\%) in Friesian cows inseminated with semen diluted and cryopreserved in 4 and $6 \%$ LDL extenders $(72.7$ and $76.7 \%)$ were significantly higher $(\mathrm{P}<0.05)$ than that of control, 8 and $10 \%$ LDL extenders $(60,61.5$ and 58.3\%, respectively). Furthermore, the best fertility rate was found using the semen diluted and cryopreserved in $6 \%$ LDL extender in compared with the other extenders (Table 4). While, the fertility rate in $10 \%$ LDL extender was slightly lower than that of control one $(58.3 .1 \%$ vs. $60 \%)$ but the differences were not significant $(\mathrm{P}>0.05)$. In addition, it was observed that the overall conception rate obtained from the all four LDL extenders were slightly higher than that of the control one $(67.1 v$ s. $60 \%, \mathrm{P}>0.05)$.

Table 1. Effect of LDL on progressive motility of bull spermatozoa (\%) at different stages of cryopreservation (Mean \pm S.E)

\begin{tabular}{|c|c|c|c|c|c|c|}
\hline \multirow{3}{*}{ Item } & \multicolumn{5}{|c|}{ Treatments } & \multirow{3}{*}{ S.E. } \\
\hline & \multirow{2}{*}{$\begin{array}{l}\text { Control } \\
\text { EY 20\% }\end{array}$} & \multicolumn{4}{|c|}{ LDL } & \\
\hline & & $4 \%$ & $6 \%$ & $8 \%$ & $10 \%$ & \\
\hline Post dilution & $62.73^{\mathrm{Ba}}$ & $66.82^{\mathrm{Aa}}$ & $68.64^{\mathrm{Aa}}$ & $60.91^{\mathrm{Ba}}$ & $60.45^{\mathrm{Ba}}$ & \pm 1.00 \\
\hline Equilibration at $5^{\circ} \mathrm{C}$ & $53.18^{\mathrm{BCb}}$ & $56.36^{\mathrm{ABb}}$ & $59.50^{\mathrm{Ab}}$ & $52.27^{\mathrm{BCb}}$ & $51.36^{\mathrm{Cb}}$ & \pm 1.40 \\
\hline Post -thaw & $43.64^{\mathrm{BCc}}$ & $46.36^{\mathrm{ABc}}$ & $49.09^{\mathrm{Ac}}$ & $43.64^{\mathrm{BCc}}$ & $41.82^{\mathrm{Cc}}$ & \pm 0.97 \\
\hline
\end{tabular}

$\mathrm{A}, \mathrm{B}, \mathrm{C}, \ldots$ the different superscripts within the same row and $\mathrm{a}, \mathrm{b}, \mathrm{c}, \ldots$ the different superscripts within the column are significant $(\mathrm{P}<0.05) . \quad \mathrm{EY}=$ Egg Yolk $\quad \mathrm{LDL}=$ Low Density Lipoprotein.

** The number of replicates for the semen evaluation at every stage of cryopreservation in this study was 96 ( $\mathrm{N}=96$ ).

Table 2. Effect of LDL on plasma membrane integrity of bull spermatozoa (\%) at different stages of cryopreservation (Mean \pm S.E)

\begin{tabular}{|c|c|c|c|c|c|c|}
\hline \multirow{3}{*}{ Item } & \multicolumn{5}{|c|}{ Treatments } & \multirow{3}{*}{ S.E. } \\
\hline & \multirow{2}{*}{$\begin{array}{l}\text { Control } \\
\text { EY 20\% }\end{array}$} & \multicolumn{4}{|c|}{ LDL } & \\
\hline & & $4 \%$ & $6 \%$ & $8 \%$ & $10 \%$ & \\
\hline Post dilution & $72.73^{\mathrm{Ca}}$ & $75.9^{\mathrm{Ba}}$ & $79.73^{\mathrm{Aa}}$ & $2.18^{\mathrm{Ca}}$ & $69.55^{\mathrm{Ca}}$ & \pm 1.10 \\
\hline Equilibration at $5^{\circ} \mathrm{C}$ & $65.64^{\mathrm{BCb}}$ & $69.45^{\mathrm{ABa}}$ & $73.91^{\mathrm{Aa}}$ & $65.09^{\mathrm{BCb}}$ & $62.00^{\mathrm{Cb}}$ & \pm 2.04 \\
\hline Post -thaw & $51.36^{\mathrm{Bc}}$ & $55.45^{\mathrm{ABb}}$ & $60.45^{\mathrm{Ab}}$ & $50.91^{\mathrm{Bc}}$ & $49.09^{\mathrm{Bc}}$ & \pm 2.71 \\
\hline
\end{tabular}

$\mathrm{A}, \mathrm{B}, \mathrm{C}, \ldots$ the different superscripts within the same row and $\mathrm{a}, \mathrm{b}, \mathrm{c}, \ldots$ the different superscripts within the same column are significant $(\mathrm{P}<0.05)$. ). $\quad \mathrm{EY}=$ Egg Yolk $\quad \mathrm{LDL}=$ Low Density Lipoprotein.

** The number of replicates for the semen evaluation at every stage of cryopreservation in this study was 96 (N=96).

Table 3. Effect of LDL on acrosome integrity of bull spermatozoa (\%) at different stages of cryopreservation $($ Mean \pm S.E)

\begin{tabular}{|c|c|c|c|c|c|c|}
\hline \multirow{3}{*}{ Item } & \multicolumn{5}{|c|}{ Treatments } & \multirow{3}{*}{ S.E. } \\
\hline & \multirow{2}{*}{$\begin{array}{l}\text { Control } \\
\text { EY 20\% }\end{array}$} & \multicolumn{4}{|c|}{ LDL } & \\
\hline & & $4 \%$ & $6 \%$ & $8 \%$ & $10 \%$ & \\
\hline Post dilution & $74.18^{\mathrm{Ca}}$ & $79.82^{\mathrm{Ba}}$ & $83.55^{\mathrm{Aa}}$ & $76.18^{\mathrm{BCa}}$ & $75.09^{\mathrm{Ca}}$ & \pm 1.01 \\
\hline Equilibration at $5^{\circ} \mathrm{C}$ & $70.16^{\mathrm{Bb}}$ & $76.55^{\mathrm{Aa}}$ & $77.18^{\mathrm{Ab}}$ & $71.09^{\mathrm{Bb}}$ & $70.36^{\mathrm{Bab}}$ & \pm 1.53 \\
\hline Post -thaw & $65.00^{\mathrm{Cb}}$ & $72.00^{\mathrm{ABb}}$ & $73.91^{\mathrm{Ab}}$ & $67.27^{\mathrm{Bb}}$ & $63.90^{\mathrm{Cb}}$ & \pm 1.85 \\
\hline
\end{tabular}

$\mathrm{A}, \mathrm{B}, \mathrm{C}, \ldots$ the different superscripts within the same row and $\mathrm{a}, \mathrm{b}, \mathrm{c}, \ldots$ the different superscripts within the same column are significant $(\mathrm{P}<0.05) . \quad \mathrm{EY}=$ Egg Yolk $\quad$ LDL= Low Density Lipoprotein.

** The number of replicates for the semen evaluation at every stage of cryopreservation in this study was 96 (N=96). 
Table 4. Conception rate of Friesian- cows inseminated with frozen semen cryopreserved in different concentrations of $\mathrm{LDL}$.

\begin{tabular}{lccc}
\hline Item & $\begin{array}{c}\text { No. of } \\
\text { inseminated females }\end{array}$ & $\begin{array}{c}\text { No. of } \\
\text { conceived females }\end{array}$ & Conception rate (\%) \\
\hline Control & 55 & 33 & $60.0^{\mathrm{B}}$ \\
$\mathbf{4 \%}$ LDL & 55 & 40 & $72.7^{\mathrm{A}}$ \\
$\mathbf{6 \%}$ LDL & 60 & 46 & $76.7^{\mathrm{A}}$ \\
$\mathbf{8 \%}$ LDL & 65 & 40 & $61.5^{\mathrm{B}}$ \\
$\mathbf{1 0 \%} \mathbf{~ L D L}$ & 60 & 35 & $58.3^{\mathrm{B}}$ \\
Overall of & 240 & 161 & $67.1^{\mathrm{B}}$ \\
LDL treatment & & & \\
\hline
\end{tabular}

$\mathrm{A}, \mathrm{B}, \ldots$ the different superscripts within the same column are significant $(\mathrm{P}<0.05)$ among treatments.

\section{DISCUSSION}

The results of the present study clearly reveal a significant effect of LDL concentrations derived from hen's egg yolk on the cryopreserved semen quality and the $6 \%$ LDL concentration was better able to protect the sperm cell from cryodamage than the other LDL concentrations tested or with the whole egg yolk. In fact, the whole egg yolk has been widely used in semen freezing extenders and proven to offer resistance against cold shock during the process of sperm freezing and thawing in several animal species (Holt, 2000; Moussa et al., 2002; and Mocé and Viecente 2009). However, the use of egg yolk has several drawbacks besides being a source of bacterial contamination (Moreno et al., 2013) and some of its constituents could have detrimental effects on spermatozoa. Accordingly, the granules found in egg yolk were observed to reduce respiration and motility of bull spermatozoa (Amiart-Briand et al., 2004). In addition, progesterone in egg yolk is responsible for the capacitation of spermatozoa and thus harmful for the preservation of spermatozoa during freezing (Bowden et al., 2001).

The presence of these detrimental substances in yolk could explain why in vitro preserved sperm quality was not as good as that recorded for the LDL extenders. These postulates may explain the higher cryopreserved sperm motility diluted and cryopreserved in $6 \%$ LDL extender compared with the egg yolk extender. The present results are consistent with that of Moussa et al. (2002) and Hu et al., (2010 and 2011) in bull; Akhter et al. (2011) in buffalo; Moustacas et al. (2011) in ram; Moreno et al. (2013) in horse, and Bencharif et al. (2010) in canine semen.

The results also showed that after semen freezingthawing, the percentages of spermatozoa with acrosome integrity and plasma membrane integrity in bull semen were higher using the $6 \%$ LDL extender than that for the control and the other LDL extenders. These results agree with the findings of $\mathrm{Hu}$ et al. (2010) who reported a higher proportion of bovine spermatozoa with plasma membrane integrity in the extender containing LDL than egg yolk. Cryopreservation is known to affect the lipid organization and chemical composition of the spermatozoa plasma membrane (Amann and Pickett,
1987). It has been assumed that LDL directly or indirectly reduces these sperm membrane modifications (Pace and Graham, 1974; Manjunath et al., 2002; Moussa, et al., 2002; Bergeron et al., 2004 and Vera-Munoz et al., 2009). It is possible that, LDL interacts specifically with bovine seminal plasma proteins (Bergeron et al., 2004). This would decrease the binding of the major proteins of bovine seminal plasma to the sperm and would prevent lipid efflux from the sperm membrane, which could explain its beneficial effects.

In the present study, when the LDL concentration was increased from 4 to $6 \% \mathrm{LDL}$, an improvement was noted in bull sperm cryopreservation. In contrast, the use of $10 \%$ LDL led to reduce post thaw sperm quality. We attribute this finding to a drop in the osmotic pressure of the extender when the LDL concentration is increased (Laffaldano et al., 2014). Moussa et al. (2002) attributed the reduction in bull sperm quality after freezing- thawing in the presence of LDL above $10 \%$ to the precipitation of fructose and salts in the extender or to LDL aggregation with consequent neutralization of its cryoprotective effect.

Regarding the results of the fertility trial, the conception rates were significantly higher $(\mathrm{P}<0.05)$ in cows artificially inseminated with semen diluted and cryopreserved in 4 and $6 \%$ LDL extenders compared with that of the control one. However, the conception rate obtained from the cows that were inseminated with the semen diluted and cryopreserved in $10 \%$ LDL extender was slightly lower than that obtained from the cows inseminated with semen cryopreserved in the control extender $(58.3 \%$ vs. $60 \%)$, however, the difference was not significant. The success rates with artificial insemination obtained from the semen diluted and cryopreserved in 4 and 6\% LDL extender $(72.7 \%$ and $76.7 \%$ ) in compared with Tris-egg yolk extender (control, 60\%), are satisfactory. In an in vitro study with bovine semen, a higher cleavage rates were observed with the semen cryopreserved in extender containing LDL than with egg yolk-based prepared extender Optidyl (Amiart-Briand et al., 2004). Whereas, in the Nili-Ravi buffalo bulls, Akhter et al. (2011) obtained a higher $(\mathrm{P}<0.01)$ fertility rate with semen cryopreserved in $10 \%$ LDL extender compared with that cryopreserved in $20 \%$ egg yolk extender. 


\section{CONCLUSIONS}

On the basis of the present results, it could be concluded that the $6 \%$ low density lipoproteins in semen extender improves the freezing ability and fertilizing capacity of bovine bull semen. Furthermore, applying this study on a large scale would make it possible to specify the impact of the LDL extender on the success of artificial insemination programs in cows. It can also be concluded that the $6 \%$ LDL concentration in extender is better to protect the bovine sperm cell from cryodamage, improves cryopreserved semen quality and fertility.

\section{REFERENCES}

Akhter S., M.S. Ansari, B.A. Rakha, S.M.H. Andrabi, M. Khalid and N. Ullah, 2011. Effect of low density lipoproteins in extender on freezability and fertility of buffalo (Bubalus bubalis) bull semen. Theriogenology, 76: 759-764.

Amann R., and B. Pickett, 1987. Principles of cryopreservation and a review of stallion spermatozoa. Equine veterinary science, 7: 145173.

Amirat-Briand L., D. Bencharif O., Vera-Munoz, S. Pineau, C. Thorin, S. Destrumelle, S. Desherces, M. Anton, M. Jouan, E. Schmidt and D. Tainturier; 2010. In vivo fertility of bull semen following cryopreservation with an LDL (low density lipoprotein) extender: Preliminary results of artificial Insemination. Animal Reproduction Science, 122: 282-287.

Amirat-Briand L., D. Tainturier, L. Jeanneau, C. Thorin, O. Gerard, J.L. Courtens and M. Anton, 2004. Bull semen in vitro fertility after cryopreser vation using egg yolk LDL: a comparison with optidyl, a commercial egg yolk extender. Theriogenology, 61: 895-907.

Animal Production Research Institute, 1997. Chapter 8: Feeding of Farm Animals. In Scientific and Practical Animal Nutrition (In Arabic) pp. 245301, Ed. By Animal Production Research Institute, Dokki, Giza, Egypt.

Bencharif D., L. Amirat, M. Anton, E. Schmitt, S. Desherces and G. Delhomme, 2008. The advantages of LDL (low density lipoproteins) in the cryopreservation of canine semen. Theriogenology, 70: 1478-1488.

Bencharif D., L. Amirat, A. Garanda, M. Anton, E. Schmitt, S. Desherces, G. Delhomme, M.L. Langloisd, P. Barrièred, S. Destrumellea, O. VeraMunoza and D.Tainturiera, 2010. Freezing canine sperm: Comparison of semen extenders containing Equex ${ }^{\circledR}$ and LDL (low density lipoproteins). Animal Reproduction Science, 119: 305-313.

Bergeron A., and P. Manjunath, 2006. New insights towards understanding the mechanisms of sperm protection by egg yolk and milk. Mol. Reprod. Dev., 73: 1338-1344.
Bergeron A., M.H. Crete, Y. Brindle and P. Manjunath, 2004. Low density lipoproteins fraction from hen's egg yolk decreases the binding of the major proteins of bovine seminal plasma to sperm and prevents lipid efflux from the sperm membrane. Biology of Reproduction, 70: 708-717.

Bowden R.M., M.A. Ewert, J.L. Lipar and C.E. Nelson, 2001. Concentration of steroid hormones in layers and biopsies of chelonian egg yolks. Endocrinology, 121: 95-103.

Celeghini E.C.C., R.P. Arruda, A.F.C. Andrade, J. Nascimento, C.F. Raphael and P.H.M. Rodrigues, 2007. Effects that bovine sperm cryopreservation using two different extenders has on sperm membranes and chromatin. Animal Reproduction Science, 100: 1-13.

El-Shamaa I., E.M. El-Seify, M.A.R. Ibrahim and M.E. El-Sharawy, 2013. Effect of addition different glutamine levels in low density lipoproteins extender on freezability and fertility of Egyptian buffalo bull's semen. In Proceedings of $4^{\text {th }}$ Scientific Conference of Animal Production Research Institute, 12-13 November, Dokki, Giza, Egypt, pp.9 -17.

El-Sharawy M.E., I.S. El-Shamaa, M.A.R. Ibrahim and M.E. El-Seify, 2012a. Using of low density lipoproteins and glutamine to improve frozen buffalo bull semen and fertility. Reproduction in Domestic Animals, 47: 444 (Abstract).

El-Sharawy M.E., I.S. El-Shamaa, M.A.R. Ibrahim, I.M. Abd El-Razek and E.M. El-Seify, 2012b. Effect of low density lipoproteins in extender on freezability and fertility of Egyptian Buffalo bull semen. Scientific paper, Animal Science Series D, LD: $114-120$.

Holt, W.V., 2000. Fundamental aspects of sperm cryobiology: the importance of species and individual differences. Theriogenology, 53: 47-58.

Hu J.H., Z.L. Jiang, L.v. RK, Q.W. Li, S.S. Zhang, L.S. Zan, Y.K. Li and X. Li, 2011. The advantages of low density lipoproteins in the cryopreservation of bull semen. Cryobiology, 62: 83-87.

Hu J.H., Q.W. Li, L.S. Zan, Z.L. Jiang, J.H. An, L.Q. Wang and Y.H. Jia, 2010. The cryoprotective effect of low-density lipoproteins in extenders on bull spermatozoa following freezing-thawing. Animal Reproduction Science, 117: 11-17.

Jeyendran R.S., H.H. Van Der Ven, M. Perez-Pelaez, B.G. Crabo and L.J.D. Zaneveled, 1984. Development of an assay to assess the functional integrity of the human sperm membrane and its relationship to other semen characteristics. J. Reprod. Fertility, 70: 219-228.

Laffaldano N., M. Di Iorio, M.P. Rosato and A. Manchisi, 2014. Cryopreservation of rabbit semen using non-permeable cryoprotectants: effectiveness of different concentrations of lowdensity lipoproteins (LDL) from egg yolk versus egg yolk or sucrose. Animal Reproduction Science, 151:220-228 
Lodhi L.A., M. Zubair, Z.I. Qureshi, I. Ahmed and H. Jamil, 2008. Correlation between hypo-osmotic swelling test and various conventional semen evaluation parameters in fresh Nili-Ravi buffalo and Sahiwal cow bull semen. Pakistan Veterinary Journal, 28: 186-188.

Manjunath P., V. Nauc, A. Bergeron and M. Menard, 2002. Major proteins of bovine seminal plasma bind to the low-density lipoprotein fraction of hen's egg yolk. Biology of Reproduction, 67: 1250-1258.

Melrose D.R., and J.A. Laing, 1970. The characteristics of normal semen In fertility and infertility in domestic animals, 2nd ed. (ed. J. A. Laing), Bailliere Tindall and Cassel . London, pp.128-160.

Mocé E., and J.S. Vicente, 2009. Rabbit sperm cryopreservation. a review, Animal Reproduction Science, 110: 1-24.

Moreno D., D. Bencharif, L. Amirat-Briand, A. Neira, S. Destrumelle and D. Tainturier, 2013. Preliminary Results: The advantages of lowdensity lipoproteins for the cryopreservation of Equine semen. Journal Equine Veterinary Science, 33: 1068-1075.

Moussa M., V. Martinet, A. Trimeche, D. Tainturier and M. Anton, 2002. Low density lipoproteins extracted from hen egg yolk by an easy method: cryoprotective effect on frozen-thawed bull semen. Theriogenology, 57: 1695-1706.

Moustacas V.S., F.G. Zaffalon, M.A. Lagares, A.M. Loaiza-Eccheverri, F.C. Varago, M.M. Neves, L.G.D. Heneine, R.P. Arruda and M. Henry, 2011. Natural but not lyophilized, low density lipoproteins were an acceptable alternative to egg yolk for cryopreservation of ram semen. Theriogenology, 75: 300-307.

Pace M.M., and E.F. Graham, 1974. Components in egg yolk which protect bull spermatozoa during freezing. Journal of Animal Science, 39: 11441149.

SAS Institute, 1999. Statistical Analysis System SAS, User's Guide Statistics. SAS Institute Inc., Cary, $\mathrm{NC}$, USA.

Vara-munoz O., L. Amirat, T. Diaz, L. Vasquez, E. Schmidt, S. Desherces, M. Anton, D. Bencharif and D. Tainturier, 2009. Effect of semen dilution to low-sperm number per dose on motility and functionality of cryoperserved bovine spermatozoa using low-density lipoproteins (LDL) extender: Comparison to Triladyl and Bioxcell. Theriogenology, 71: 895-900.

Watson P.F., 1975. The interaction of egg yolk and ram spermatozoa studied with a fluorescent probe. Journal of Reproduction and Fertility, 42:105-111.

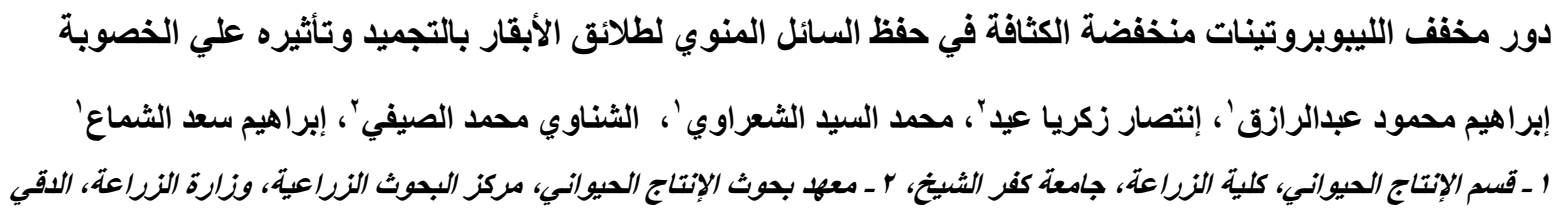

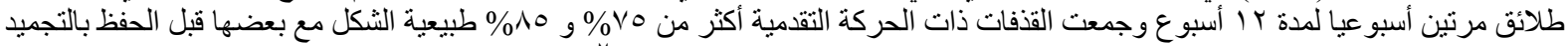

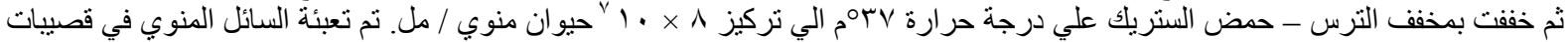

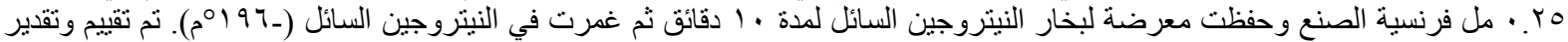

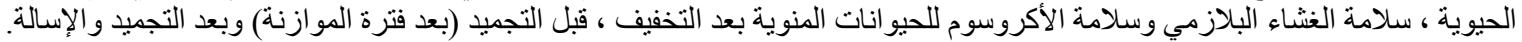

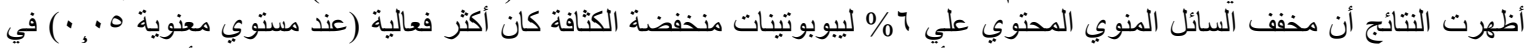

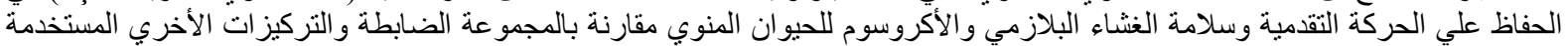

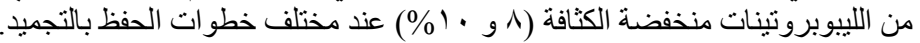

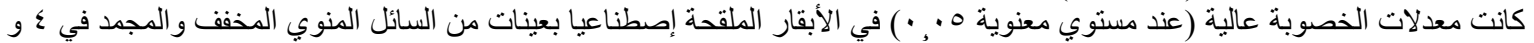

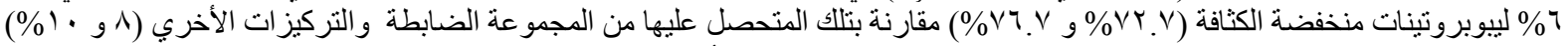

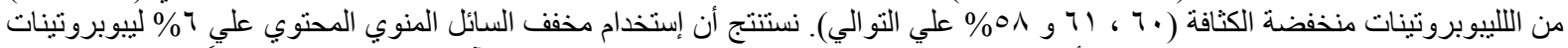

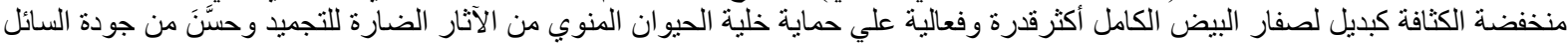

